\title{
Fibrosing mediastinitis: Successful stenting of the pulmonary artery
}

\author{
Rennae Thiessen MD FRCPC ${ }^{1}$, Fred Matzinger MD FRCP ${ }^{1}$, Jean Seely MD FRCP ${ }^{1}$, \\ Rima Aina MD FRCP ${ }^{1}$, Peter MacLeod MD FRCP ${ }^{2}$
}

\begin{abstract}
R Thiessen, F Matzinger, J Seely, R Aina, P MacLeod. Fibrosing mediastinitis: Successful stenting of the pulmonary artery. Can Respir J 2008;15(1):41-44.

Fibrosing mediastinitis is a rare benign condition, which can cause compression of the pulmonary or systemic vessels, tracheobronchial tree, coronary arteries or esophagus, leading to disabling clinical symptoms and even death. The case of a 26-year-old woman who presented with dyspnea is described. She was found to have $80 \%$ stenosis of the right pulmonary artery secondary to fibrosing mediastinitis. The stenosis was managed successfully with an endovascular PalmazSchatz stent, and the patient remains symptom-free 10 years later.
\end{abstract}

\section{Une médiastinite fibreuse : Installation réussie d'une endoprothèse dans l'artère pulmonaire}

La médiastinite fibreuse est un trouble rare et bénin qui peut provoquer la compression des vaisseaux pulmonaires ou systémiques, de l'arbre trachéobronchique, des artères coronaires ou de l'œsophage, et ainsi entraîner des symptômes cliniques invalidants et même la mort. Est décrit le cas d'une femme de 26 ans qui a consulté en raison d'une dyspnée. Elle souffrait d'une sténose de $80 \%$ de l'artère pulmonaire droite, causée par une médiastinite fibreuse. La sténose a été traitée avec succès grâce à l'installation d'une endoprothèse Palmaz-Schatz endovasculaire. Dix ans plus tard, la patiente demeure asymptomatique.

Key Words: Fibrosing mediastinitis; Palmaz-Schatz stent; Pulmonary artery stenosis

Cibrosing mediastinitis (FM) is a rare benign condition char- acterized pathologically by proliferation of acellular collagen and fibrous tissue within the mediastinum (1). This fibrous reaction can lead to compression or occlusion of mediastinal structures with debilitating clinical symptoms (2). We report a case of successful percutaneous angioplasty and intravascular stenting of the right pulmonary artery (PA) for stenosis secondary to FM.

\section{CASE PRESENTATION}

A 26-year-old woman, who was a life-long nonsmoker, presented to her family physician complaining of exertional dyspnea. Her past medical history was positive for pericarditis at 12 years of age. Physical examination was normal. Chest $\mathrm{x}$-ray (CXR) at a nearby community hospital was interpreted as showing bilateral hilar adenopathy with a normal mediastinum, lungs and pleura. Bronchoscopy revealed normal mucosa, and the transbronchial biopsy showed no pathological changes. Sarcoidosis was the working diagnosis. She received no treatment.

Her exertional dyspnea was persistent, and she presented again to her family physician one year after initiation of symptoms. CXR was now interpreted as showing decreased pulmonary vascularity of the right lung, a $5 \mathrm{~mm}$ right middle lobe lung nodule and very faint central mediastinal calcifications. There was no hilar adenopathy (Figure 1). A computed tomography $(\mathrm{CT})$ scan of the chest performed with and without intravenous contrast enhancement revealed extensive mediastinal

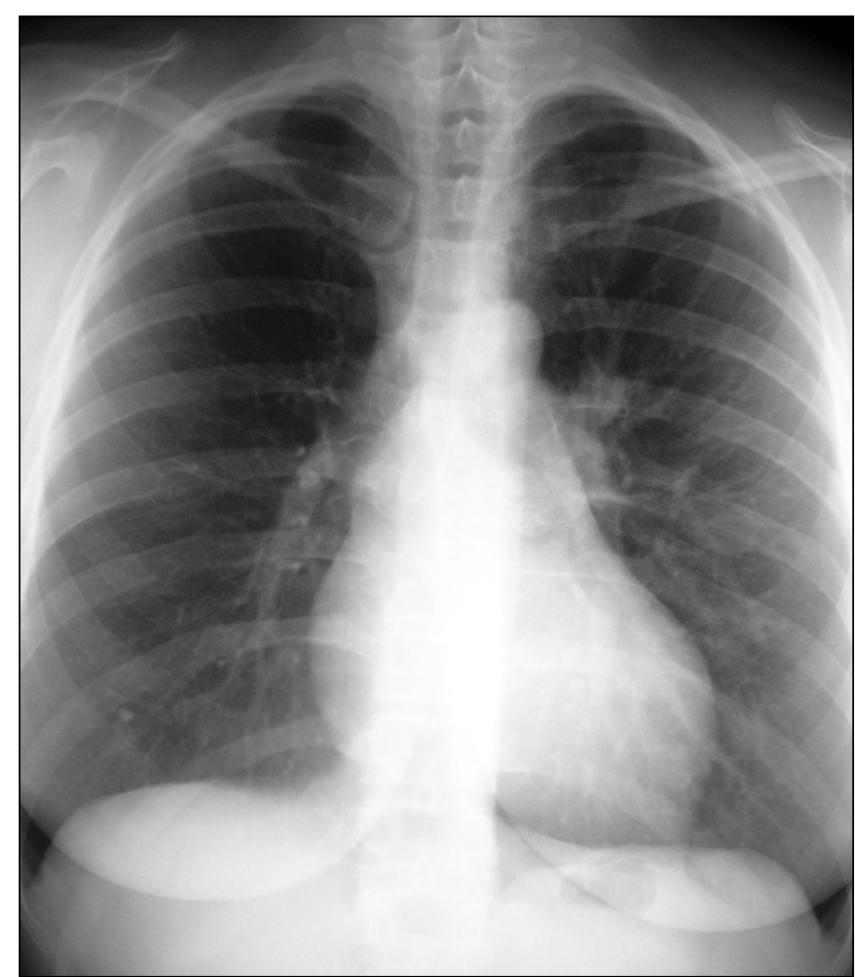

Figure 1) Chest x-ray (posterior anterior view) showing a subtle decrease in size of the right hilum and pulmonary vessels in the right lung, and a $5 \mathrm{~mm}$ right middle lobe nodule 

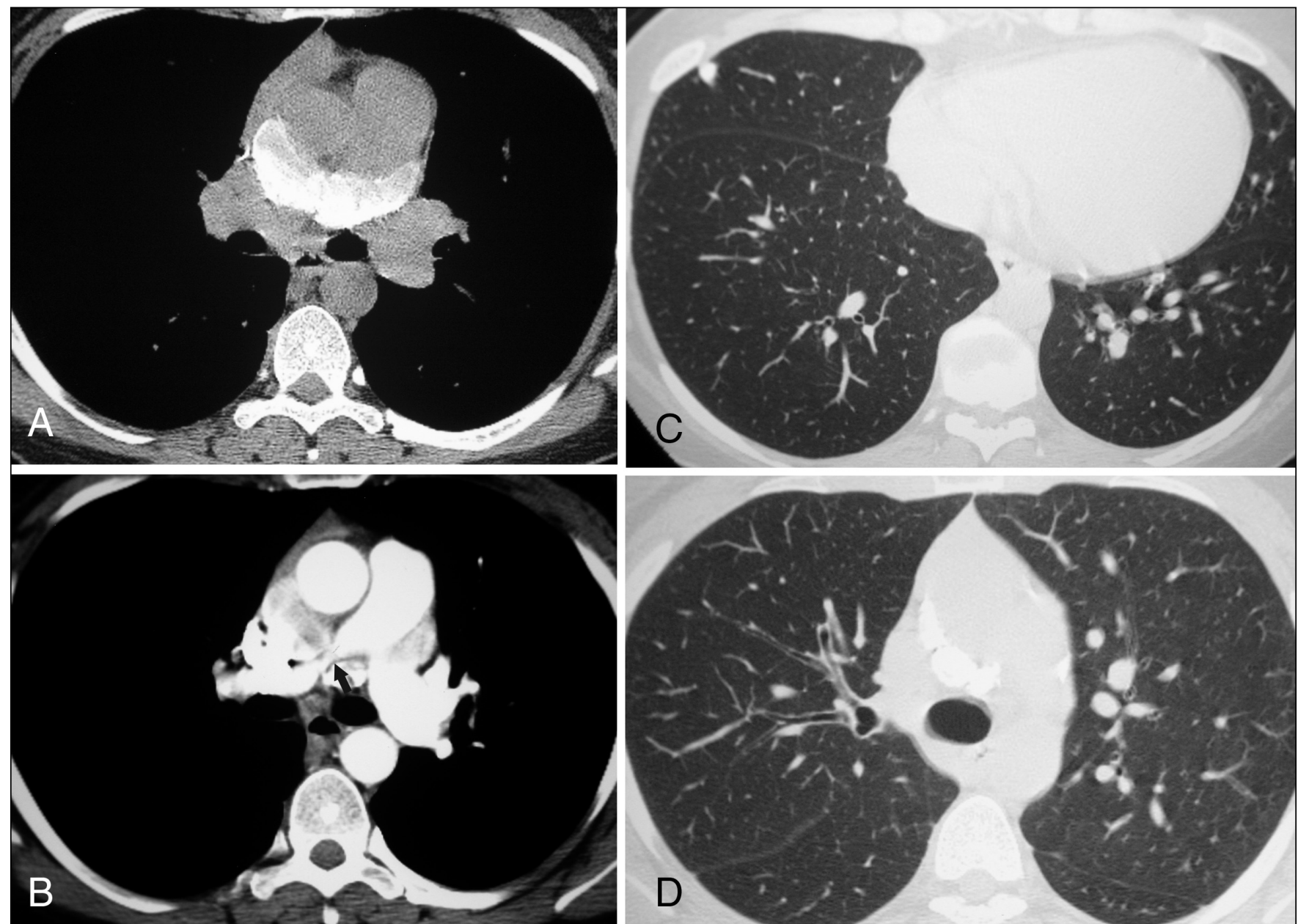

Figure 2) A Computed tomography (CT) scan of the thorax without intravenous contrast shows encasement of the right pulmonary artery with calcification. B CT scan of the thorax with intravenous contrast shows severe narrowing (arrow) of the right pulmonary artery. C CT scan of the lungs shows a calcified right middle lobe granuloma. D CT scan of the lungs shows smaller calibre vessels of the right lung

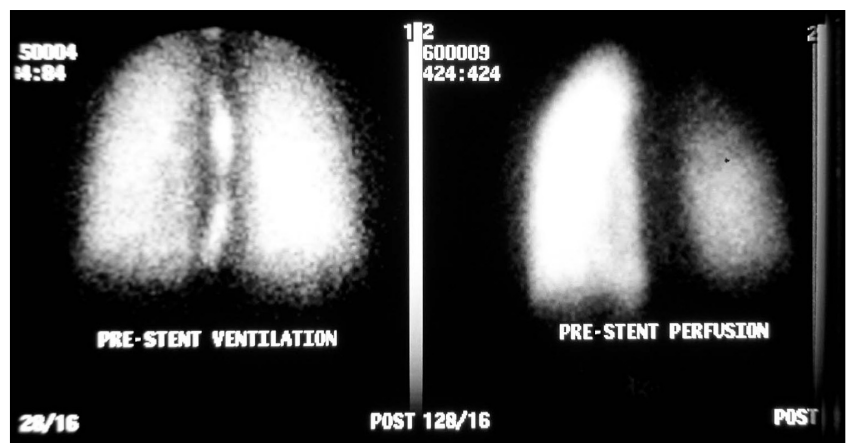

Figure 3) Ventilation and perfusion scan (posterior view) of the lungs before stent insertion, showing $78.5 \%$ perfusion to the left lung, $21.5 \%$ perfusion to the right lung and normal ventilation

calcifications that encased and severely narrowed the right $\mathrm{PA}$, a calcified $5 \mathrm{~mm}$ right middle lobe granuloma and an overall decrease in size of the pulmonary arteries in the right lung (Figure 2). The pulmonary veins were patent and normal in appearance. The lung parenchyma was normal. A diagnosis of FM was established based on characteristic imaging findings, possibly associated with previous Histoplasma capsulatum infection. Pulmonary function tests showed a normal forced vital capacity, forced expiratory volume in $1 \mathrm{~s}$ and peak expiratory flow rate. Stage I exercise testing was characterized by high dead space ventilation with decreased cardiac response to exercise, consistent with $70 \%$ of maximum predicted workload. The maximum oxygen uptake achieved was $1.4 \mathrm{~mL} / \mathrm{kg} / \mathrm{min}$, which was $65 \%$ of predicted. Gallium scan of the thorax was normal. A quantitative ventilation-perfusion $(\mathrm{V} / \mathrm{Q})$ scan demonstrated $21.5 \%$ perfusion to the right lung, $78.5 \%$ perfusion to the left lung and normal ventilation (Figure 3). Dyspnea was progressive over the next eight months, and she was referred to a thoracic surgeon. At that time, she complained of central nonexertional chest pain. Her physical examination, biochemistry, and hematology screenings were normal. The presence of $H$ capsulatum was negative using immunodiffusion and complement fixation tests. Antinuclear antibody testing was positive with a speckled pattern and titre of 1:80. Repeat CXR, CT and V/Q scans showed no significant change. Her electrocardiogram was normal. Her echocardiogram confirmed previous CT findings of calcification surrounding the right PA that extended along the medial aspect of the main PA, with a diminished calibre of the right PA. Left and right ventricular size and function were normal. She was in New York Heart Association (NYHA) class II in terms of disability, was unable 
to participate in athletic activities and had given up playing hockey - a sport that she had enjoyed playing for many years. Therefore, an endovascular intervention was undertaken.

Right heart catheterization and pulmonary angiogram were performed, confirming a discrete fusiform narrowing of the proximal one-third of the right main PA because of external compression of the artery by calcified lymph nodes. The opacified lumen measured only $3 \mathrm{~mm}$. Intravascular pressure gradients were measured in the left main PA $(39 / 8 \mathrm{mmHg}$ [systolic/diastolic], with a mean of $19 \mathrm{mmHg}$ ), and in the right main PA beyond the area of stenosis $(18 / 6 \mathrm{mmHg}$ [systolic/diastolic], with a mean of $10 \mathrm{mmHg}$ ). Therefore, there was a significant pressure gradient with nonphasic distal pressure, warranting percutaneous intervention. The right PA was dilated with a $15 \mathrm{~mm} \times 3 \mathrm{~cm}$ Mansfield (Boston Scientific, USA) balloon. Postangioplasty angiogram showed the lumen had expanded from $3 \mathrm{~mm}$ to $10.1 \mathrm{~mm}$, thereby reducing the stenosis from $80 \%$ to $20 \%$. Following the angioplasty, a $3 \mathrm{~cm}$ long $8 \mathrm{~mm}$ to $12 \mathrm{~mm}$ Palmaz-Schatz stent (Cordis, USA) was deployed in the right PA and expanded to $10 \mathrm{~mm}$. The patient experienced transient chest pain with stent placement, which resolved within minutes. A follow-up angiogram showed significant improvement in the right PA diameter. There was a residual mean pressure gradient of approximately $3 \mathrm{mmHg}$, with good phasic pressure pulse beyond the stent.

Follow-up CXR showed good positioning of the stent and an increase in diameter of the right lower lobe PA. She remained on intravenous heparin for $24 \mathrm{~h}$ and was discharged on acetylsalicylic acid (325 mg daily) for three months.

One month postprocedure, she was able to return to playing recreational hockey. A quantitative $\mathrm{V} / \mathrm{Q}$ scan showed a significant increase in perfusion to the right lung from $21 \%$ to $55 \%$. The perfusion to the left lung had decreased from $80 \%$ to $45 \%$. A repeat $\mathrm{V} / \mathrm{Q}$ scan approximately four months postprocedure showed perfusion to the right lung at $51 \%$. A repeat exercise test was not performed given her dramatic clinical improvement and the favourable results of the quantitative perfusion scans following stent placement.

Six months postprocedure the patient underwent right heart catheterization and pulmonary angiogram, which demonstrated a $5 \mathrm{mmHg}$ mean gradient across the right PA and a $65 \%$ intrastent stenosis. Stent angioplasty was successfully performed with an $18 \mathrm{~mm} \times 3 \mathrm{~cm}$ Mansfield balloon. A postangioplasty angiogram showed approximately $30 \%$ residual stenosis. The patient remains asymptomatic 10 years postprocedure. The most recent transesophageal and transthoracic echocardiography examination showed a mild intrastent (systolic) gradient of $13 \mathrm{mmHg}$, which had decreased since the previous examination. The most recent CT of the thorax showed the endovascular stent in good position (Figure 4), with no discernible narrowing of the right PA or its branches.

\section{DISCUSSION}

FM was first described by Oulmont in 1855 and was believed to be secondary to syphilis or tuberculosis until 1925 when an association with fungal infections was proposed by Knox (3). The precise etiology and pathogenesis of FM remains unknown despite extensive research. There has been a suggested link to $H$ capsulatum infection in many North American cases. Because histopathological confirmation is lacking in many

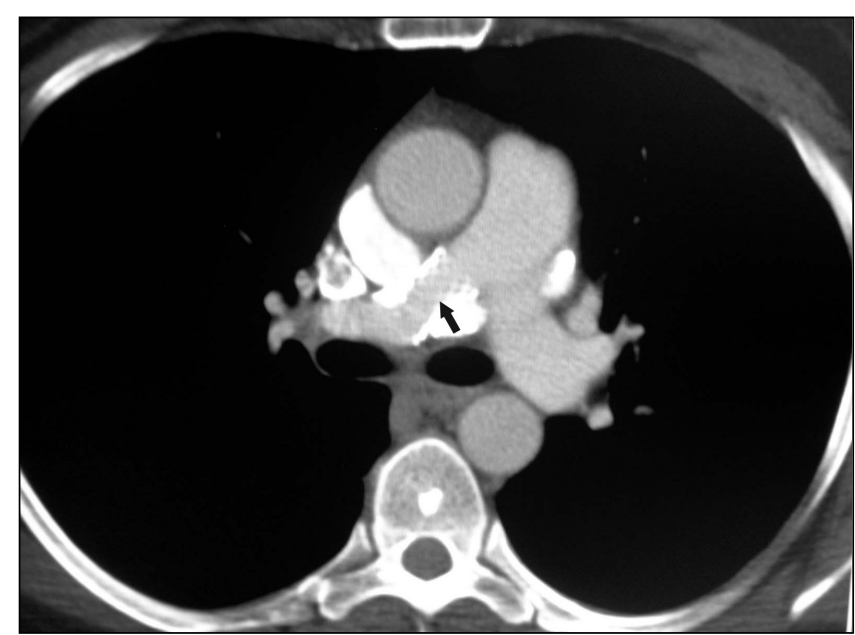

Figure 4) Computed tomography scan with contrast shows stent (arrow) well positioned in right pulmonary artery

cases, it has been proposed that the link between $H$ capsulatum and FM involves an abnormal hypersensitivity reaction to $H$ capsulatum antigens rather than direct infection of the mediastium (1). Other etiologies have also been cited, including other infectious, and autoimmune and idiopathic fibroinflammatory causes $(1,2,4)$.

Two distinct types of FM have been described. The first is believed to be linked to granulomatous disease, most commonly $H$ capsulatum, and shows localized calcified involvement of the mediastinum. The second form has diffuse noncalcified involvement of the mediastinum and may occur idiopathically or be related to some other autoimmune or fibroinflammatory disease $(1,2,4)$. It has been proposed by Weinstein et al $(5)$, and supported by others, that CT findings of a localized soft tissue mass containing calcification in a patient with appropriate clinical history are substantive for diagnosis, in which case tissue sampling is not needed (2).

The most common mediastinal structure to be involved with FM is the superior vena cava (2); however, pulmonary veins, arteries, the tracheobronchial tree, esophagus, pericardium and coronary arteries may also be affected $(2,4)$. The clinical manifestations of FM relate to the structures that are intimately affected and include symptoms such as exertional dyspnea, cough, hemoptysis or superior vena cava obstruction syndrome. Pharmacological treatment with steroids or antifungal agents has been largely unsuccessful $(6,7)$. The lack of a well-defined surgical plane of dissection makes open surgical intervention difficult and has been associated with high morbidity and mortality (7). Endovascular stenting of the PA is a feasible intervention for isolated stenosis of the PA.

Our patient was in NYHA class II and, therefore, endovascular stenting of the obstructed right PA was undertaken.

The patient's dyspnea was believed to be a result of dead space ventilation. However, before restoring blood flow to the PA, careful evaluation to rule out concomitant pulmonary venous obstruction or airway obstruction should be carried out to avoid subsequent development of pulmonary edema or severe shunting (7). This is accomplished by careful assessment of the airways and pulmonary veins on the pretreatment contrast-enhanced CT scan. Although endovascular stenting precludes many of the risks associated with open thoracotomy, potential complications include 
infection, stent migration, embolization and restenosis. To circumvent the thrombogenic nature of stainless steel stents, antiplatelet therapy is recommended until neoendothelialization has taken place (8). Prophylactic antibiotic treatment was recommended to our patient before dental procedures to avert risk of infection. Reangioplasty is relatively noninvasive and may be undertaken if restenosis occurs within the intravascular stent (4).

\section{REFERENCES}

1. Rossi SE, McAdams HP, Rosado-de-Christenson ML, Franks TJ, Galvin JR. Fibrosing Mediastinitis. Radiographics 2001;21:737-57.

2. Sherrick AD, Brown LR, Harms GF, Myers JL. The radiographic findings of fibrosing mediastinitis. Chest 1994;106:484-9.

3. Guerrero A, Hoffer EK, Hudson L, Schuler P, Karmy-Jones R. Treatment of pulmonary artery compression due to fibrous mediastinitis with endovascular stent placement. Chest 2001;119:966-8.

4. Kandzari DE, Warner JJ, O'Laughlin MP, Harrison JK. Percutaneous stenting of right pulmonary artery stenosis in fibrosing mediastinitis. Catheter Cardiovasc Interv 2000;49:321-4.

5. Weinstein JB, Aronberg DJ, Sagel SS. CT of fibrosing mediastinitis: findings and their utility. AJR Am J Roentgenol 1983;141:247-51

\section{CONCLUSIONS}

A review of the English literature reveals that endovascular stenting of the PA secondary to FM has been reported in only seven patients $(2,4,7,9)$. Our patient was in NYHA class II and has now resumed athletic activities for 10 years postprocedure. Although experience is still limited, percutaneous stenting of the PA for relief of stenosis secondary to FM proves promising as a therapeutic option.

6. Robbins IM, Davis AM, Doyle TP, Loyd JE. Pulmonary artery stenosis and fibrous mediastinitis. Chest 2001;120:1750-1.

7. Doyle TP, Loyd JE, Robbins IM. Percutaneous pulmonary artery and vein stenting: A novel treatment for mediastinal fibrosis. Am J Respir Crit Care Med 2001;164:657-60.

8. Dodds GA 3rd, Harrison JK, O'Laughlin MP, Wilson JS, Kisslo KB, Bashore TM. Relief of superior vena cava syndrome due to fibrosing mediastinitis using the Palmaz stent. Chest 1994;106:315-8.

9. Fontaine AB, Borsa JJ, Hoffer EK, Bloch RD, So C. Stent placement in the treatment of pulmonary artery stenosis secondary to fibrosing mediastinitis. J Vasc Interv Radiol 2001;12:1107-11. 


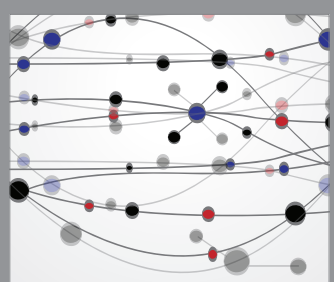

The Scientific World Journal
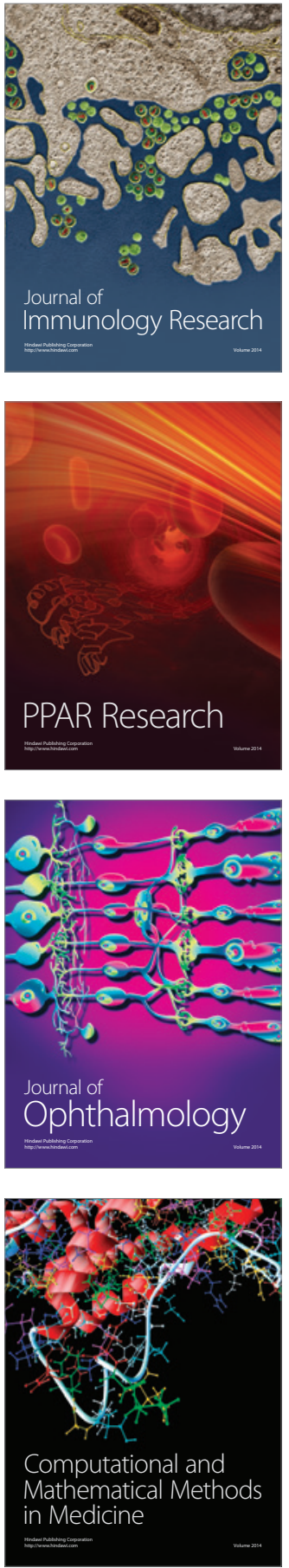

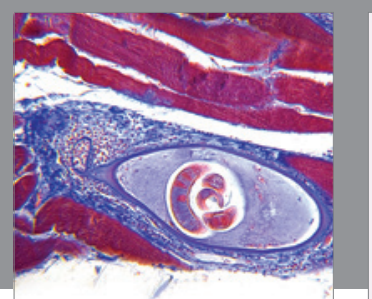

Gastroenterology Research and Practice

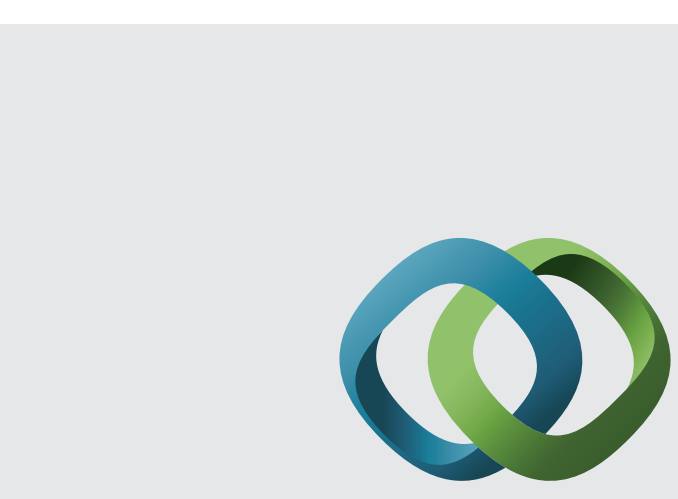

\section{Hindawi}

Submit your manuscripts at

http://www.hindawi.com
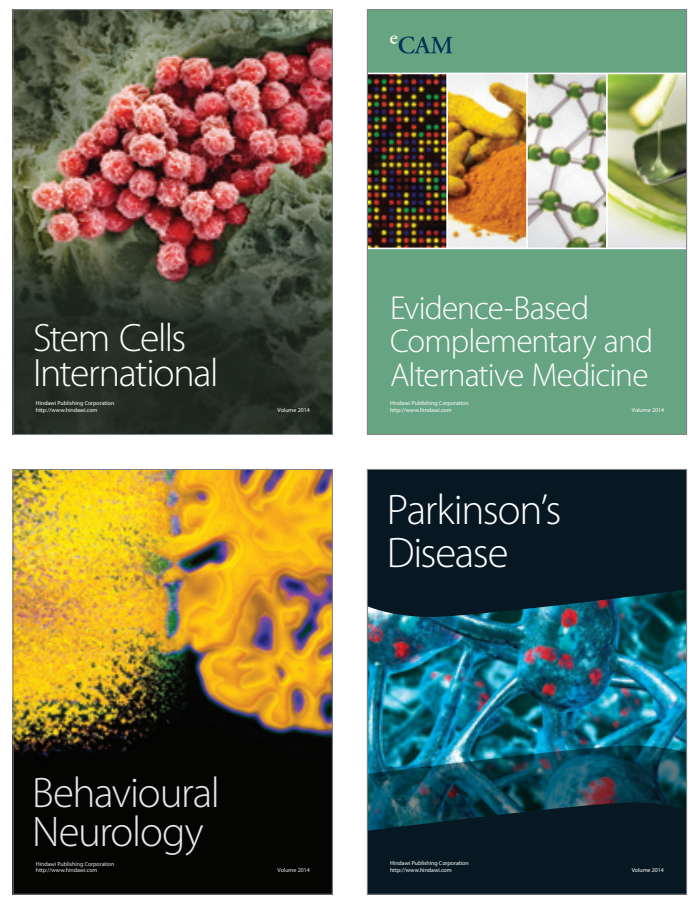
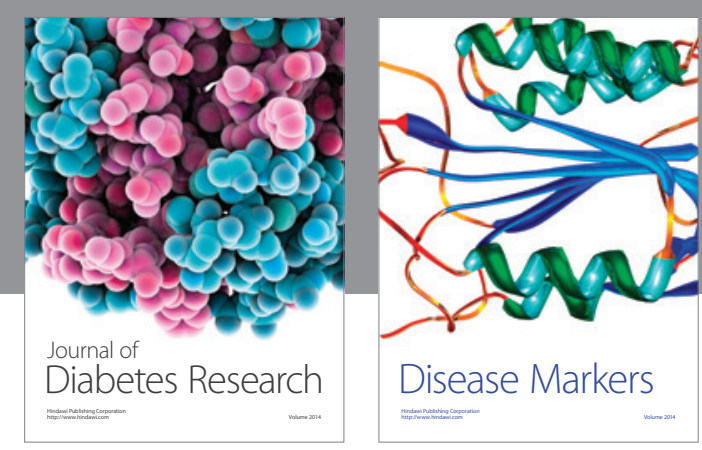

Disease Markers
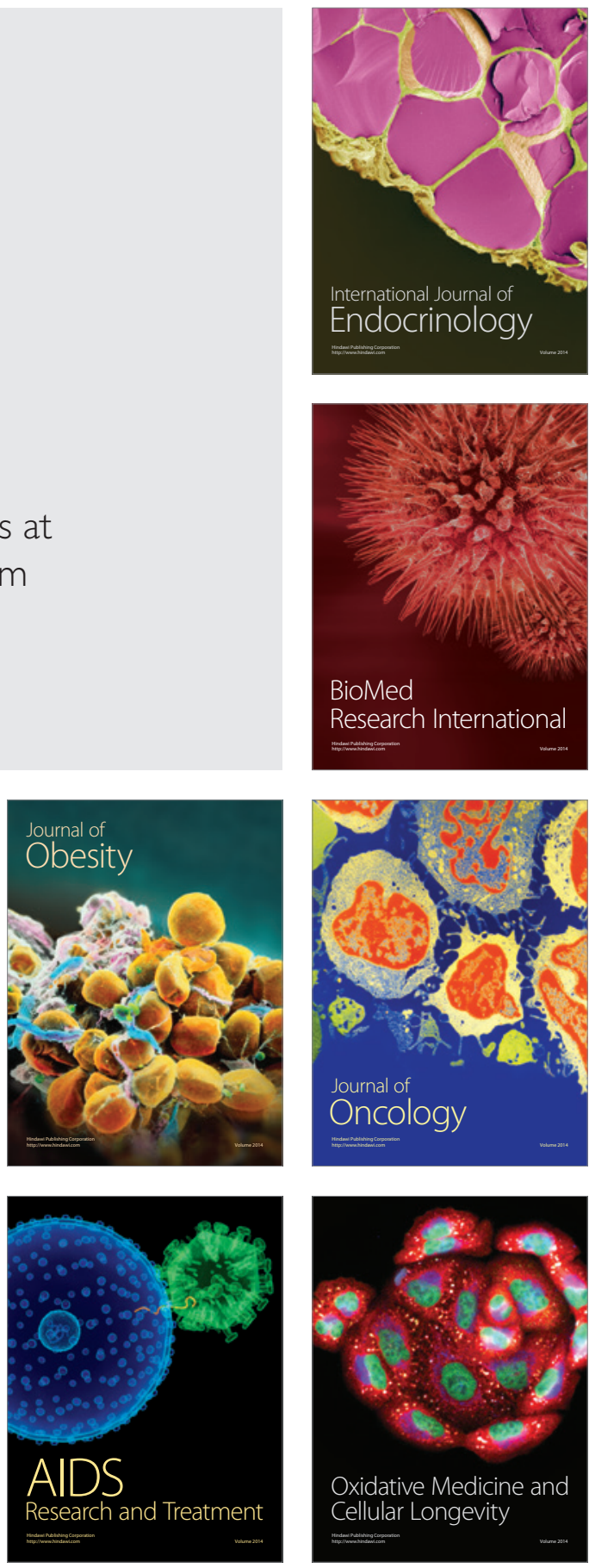